\title{
Editor's Note: Taking (A)part: Investigations into Participation
}

Seeking common threads among the articles in this issue of DRJ, I want to suggest a thematic continuity in the role of participation as a methodology of performance and research and as a category of identity and difference in dance culturally, critically, and historically. Participation can be thought of as a "taking (a) part in," but also as the undoing and remaking of conventional forms of representation, and hence of theatrical role-playing as well as conventions of belonging. The tension between these two ways of understanding participation as both taking part in and taking apart can be extended across a range of phenomena that include but also exceed concert dance, and such reframing and dismantling of "participatory dance" actually highlights the engagement of spectators as doers on multiple levels. The range of diverse performative genres under discussion in this issue of $D R J$ is notable.

In "Current Trends in Contemporary Choreography: A Political Critique," Alexandra Kolb examines how fault lines between criticism, late capitalist economies, and choreographic performance have shifted since the 1960s. She asks whether aesthetic innovation has kept pace with these shifts. Kolb perceives a connection between the move toward collaborative performance-in which the choreographic work is no longer the output of one choreographic mind-and current immersive performance in which the audience is called upon to perform, or at least to actively experience, and thus to contribute to the work. While the abandonment of choreographic authority was considered democratic in the 1960s, does the immersive engagement of an "experience economy" represent another step toward political enlightenment or a step backward? Is the participatory, in other terms, de facto democratic and, indeed, an expression of radical democracy?

In "The Muse of Virtuosity: Desmond Richardson, Race, and Choreographic Falsetto," Ariel Osterweis questions the presumed political radicality of minimalism and stillness with respect to the virtuosic aesthetic of Desmond Richardson in the work of Dwight Rhoden for the dance company Complexions Contemporary Ballet. Put into question here is the phenomenon of virtuosity itself, which has been theorized since the nineteenth century as a non-participatory art expression: the virtuoso does for us what we cannot do, reducing us to mere spectators. Osterweis counters this idée recue by reclaiming virtuosity's redemptive force within a black aesthetic, and, using the musical metaphor of falsetto, for a "queer of color" aesthetic on the dividing line between popular and "high" art. The question here is how to conceive of these virtuosic practices as participating in the choreographic avant-garde, which has since the 1960s disqualified virtuosity.

Sherril Dodds in "Embodied Transformations in Neo-Burlesque Striptease" identifies areas of transformation of traditional burlesque performance in the purview of the neo-burlesque alongside and within "a shifting matrix of class, gender, and moral values" (p. 78). These transformations include idealizations of feminine beauty as well as re-conceptualizations of the female erotic. Based in part on ethnographic research - including auto-ethnography-and an analysis of audience reaction, Dodds brings the transformative potential of neo burlesque into relation with "[T]he blurring of the performer/audience division" (p. 83). That is, the conventional lines of participation are

(1)


set in motion by new economies of transformation, although these changes must be weighed against the social realities of the performers in question.

Rumya S. Putcha analyzes the participation in modernity of the concept of classical Indian dance in "Between History and Historiography: The Origins of Classical Kuchipudi Dance." This essay contributes to the critical literature on the invention of tradition in classical Indian dance forms. In particular, "Kuchipudi as a modern symbol of a Telugu identity" (p. 93) participates in both history and historiography at the intersection of dance and regional linguistic identities with respect to modern national identities. The complex game of inclusions and exclusions makes the point that regionalism and its politics are distinct from nationalism.

In "Dance, Interactive Technology, and the Device Paradigm," Eric Mullis explores the intersection of the body with digital technology in contemporary dance performance. Mullis specifically addresses issues of bidirectionality and technological mediation in the interaction between the dancer and the device. To what degree is there a phenomenological interaction between body and technology in interactive platforms that provides for feedback between the dancer and the device? Recalling in some ways Kolb's discussion of immersive performance in a very different setting, as well as Dodd's discussion of audience, performer, and performance in neo-burlesque, Mullis is weighing the relative values of participation that constitute an exchange represented as happening - but does it really?- thanks to the device that transforms traditional means of choreographic representation.

Cindy García’s “The Great Migration: Los Angeles Salsa Speculations and the Performance of Latinidad" introduces a heterogeneous map of social dance establishments in Los Angeles that showcase salsa music and dancing as part of their nightlife repertoires. García discusses the assignation of class or immigration status to specific music/dance genres or stylistic approaches to them by engaging ethnographic data on a dance culture little acknowledged in the discipline of dance studies. Here, questions of identity are performed and assessed in relation to a set of possible participatory strategies within one extended, yet also fractured, community.

The Dialogue in this issue is taken from a roundtable discussion held at Brown University in June 2013 - Inside/Beside Dance Studies—as part of the Mellon Summer Seminar. The interdisciplinary framework of the seminar, which pairs dance with the humanities, raises the question (and the stakes) of their co-participation. I wish to thank all the participants in that roundtable, and especially Noémie Bernier-Solomon for her curation of this dialogue.

Mark Franko

Editor, Dance Research Journal 